\title{
Article \\ Age and Serum AMH and FSH Levels as Predictors of the Number of Oocytes Retrieved from Chromosomal Translocation Carriers after Controlled Ovarian Hyperstimulation: Applicability and Limitations
}

\author{
Yulia V. Shilenkova ${ }^{1}$ (D), Anna A. Pendina ${ }^{1}$, Irina D. Mekina ${ }^{1}$, Olga A. Efimova ${ }^{1, *(D)}$, Evgeniia M. Komarova ${ }^{1}$, \\ Elena A. Lesik ${ }^{1}$, Mariia A. Ishchuk ${ }^{1}$ (D), Elena M. Fedorova ${ }^{2}$, Olga G. Chiryaeva ${ }^{1}$, Lubov' I. Petrova ${ }^{1}$, \\ Vera S. Dudkina ${ }^{1}$, Olga E. Talantova ${ }^{1}$, Alexander M. Gzgzyan ${ }^{1}$ and Igor Yu. Kogan ${ }^{1}$ \\ 1 D.O. Ott Research Institute of Obstetrics, Gynecology and Reproductology, 199034 St. Petersburg, Russia; \\ shil.giulia@gmail.com (Y.V.S.); pendina@mail.ru (A.A.P.); irendf@mail.ru (I.D.M.); \\ evgmkomarova@gmail.com (E.M.K.); lesike@yandex.ru (E.A.L.); mashamazilina@gmail.com (M.A.I.); \\ chiryaeva@mail.ru (O.G.C.); petrovaluba@mail.ru (L.I.P.); dudkinavs@mail.ru (V.S.D.); \\ olga_talantova@mail.ru (O.E.T.); agzgzyan@mail.ru (A.M.G.); ikogan@mail.ru (I.Y.K.) \\ 2 AVA-Peter Clinic, 191014 St. Petersburg, Russia; fedorova-em@avaclinic.ru \\ * Correspondence: efimova_o82@mail.ru; Tel.: +7-812-328-9809
}

Citation: Shilenkova, Y.V.; Pendina A.A.; Mekina, I.D.; Efimova, O.A.; Komarova, E.M.; Lesik, E.A.; Ishchuk, M.A.; Fedorova, E.M.; Chiryaeva O.G.; Petrova, L.I.; et al. Age and Serum AMH and FSH Levels as Predictors of the Number of Oocytes Retrieved from Chromosomal Translocation Carriers after Controlled Ovarian Hyperstimulation: Applicability and Limitations. Genes 2021, 12, 18. https://dx.doi.org/10.3390/ genes12010018

Received: 28 October 2020 Accepted: 21 December 2020 Published: 25 December 2020

Publisher's Note: MDPI stays neutral with regard to jurisdictional claims in published maps and institutional affiliations.

Copyright: () 2020 by the authors. Licensee MDPI, Basel, Switzerland. This article is an open access article distributed under the terms and conditions of the Creative Commons Attribution (CC BY) license (https: / / creativecommons.org/ licenses/by/4.0/).

\begin{abstract}
We studied the impact of age and the serum anti-Müllerian hormone (AMH)/folliclestimulating hormone (FSH) levels on the number of cumulus-oocyte complexes (COCs) retrieved from female reciprocal and Robertsonian translocation carriers after controlled ovarian hyperstimulation $(\mathrm{COH})$. The number of $\mathrm{COCs}$ retrieved after $\mathrm{COH}$ was retrospectively analyzed in female translocation carriers and 46,XX partners of male translocation carriers from 100 couples. The median number of COCs varied from nine to 16 and did not differ among subgroups of women categorized by age, presence and type of a translocation. The number of COCs correlated negatively with the woman's age in both the reciprocal and the Robertsonian translocation carriers, while in $46, \mathrm{XX}$ women no correlation was detected. The number of COCs did not differ between the reciprocal and the Robertsonian translocation carriers aged either $<35$ or $\geq 35$ years. In translocation carriers, the number of COCs correlated with the serum AMH level only in the younger-age subgroups; the correlation was strong positive in reciprocal and moderate positive in Robertsonian translocation carriers. The $46, \mathrm{XX}$ women aged both $<35$ and $\geq 35$ years showed similar moderate positive correlations. Across all subgroups, the number of COCs correlated moderately negatively with the serum FSH level only in Robertsonian translocation carriers aged $<35$ years. Our results suggest that chromosomal translocations per se do not increase the risk of poor oocyte retrieval outcome after $\mathrm{COH}$. In translocation carriers, oocyte retrieval outcome depends to a large extent on their age. The serum AMH level strongly predicts oocyte retrieval outcomes only in young reciprocal translocation carriers, while the serum FSH level has a moderate predictive value in young Robertsonian translocation carriers.
\end{abstract}

Keywords: translocation carriers; oocyte retrieval; IVF; PGT-SR; female age; anti-Müllerian hormone $(\mathrm{AMH})$; follicle-stimulating hormone (FSH)

\section{Introduction}

A frequent occurrence in the modern world, reproductive disorders are regarded as one of the primary public health challenges. Considering the significant contribution of genetic factors to these disorders [1], in particular, to infertility and pregnancy loss, genomic analysis on different levels of genome organization-from individual genes to chromosome sets-has become an integral part of reproductive medicine. 
A common genetic cause of reproductive disorders in a couple is a balanced chromosomal rearrangement in one of the partners. The most widespread and clinically significant chromosomal rearrangements are translocations: reciprocal, an exchange of material between non-homologous chromosomes, and Robertsonian, a centric fusion of two acrocentric autosomes [2]. Characterized by the absence of either gain or loss of genetic material, balanced chromosomal rearrangements do not result in phenotypic changes in their carriers but may, however, lead to the production of chromosomally unbalanced gametes. When unbalanced oocytes and/or spermatozoa participate in fertilization, the resulting embryos are also chromosomally unbalanced. This, in turn, leads to anomalies or arrest of embryonic development and therefore to unfavorable reproductive outcomes, such as infertility, implantation failure during in vitro fertilization (IVF) cycles, pregnancy loss or chromosomally abnormal offspring [3]. To address fertility issues in couples where one of the partners is a translocation carrier, preimplantation genetic testing for structural rearrangement (PGT-SR) is widely used [4,5]. It is in such couples that the optimal number of oocytes retrieved after controlled ovarian hyperstimulation $(\mathrm{COH})$ is key to IVF/PGT-SR efficiency. The probability of producing normal/balanced oocytes is considerably lower in female translocation carriers than in karyotypically normal women: only 1:8 in reciprocal translocation carriers and 1:16 in Robertsonian translocation carriers [3]. Research into the specifics of ovarian response and factors contributing to this process in female translocation carriers is, therefore, a vital measure for the successful conception and birth of a healthy child.

The aim of the present study was to analyze the number of cumulus-oocyte complexes $(\mathrm{COCs})$ retrieved from female reciprocal and Robertsonian translocation carriers after $\mathrm{COH}$ and to verify the possible correlation with the woman's age and the serum level of antiMüllerian hormone (AMH) and follicle-stimulating hormone (FSH).

\section{Materials and Methods}

\subsection{Patients}

The study retrospectively included 137 IVF cycles in 100 couples who were referred to the D.O. Ott Research Institute of Obstetrics, Gynecology and Reproductology (St. Petersburg, Russia) or the AVA-Peter Clinic (St. Petersburg, Russia) for IVF/PGT-SR for balanced translocations in the period from March 2009 to May 2019. The number of COCs retrieved after $\mathrm{COH}$ in female translocation carriers was compared to that in karyotypically normal partners of male translocation carriers.

\subsection{Karyotype Verification}

All of the couples referred for IVF/PGT-SR already had a cytogenetic diagnosis. In all of the cases, the initial indications for karyotyping were infertility or pregnancy loss. Prior to the start of an IVF/PGT-SR cycle, cytogenetic diagnoses in all of the translocation carriers were verified by conventional karyotyping followed by fluorescence in situ hybridization (FISH) if required. All conventional karyotyping and FISH procedures including PHA-stimulation of peripheral blood lymphocytes, preparation of metaphase chromosomes, QFH/AcD staining and hybridization were performed according to standard protocols with modifications repeatedly used in our previous studies [6-10]. The final cytogenetic diagnoses are summarized in Table A1. In 52 out of 100 couples, balanced translocation carriers were women (31 cases of reciprocal translocations and 21 cases of Robertsonian translocations). In the remaining 48 couples, balanced translocation carriers were men (27 cases of reciprocal translocations and 21 cases of Robertsonian translocations).

\subsection{Controlled Ovarian Hyperstimulation}

Before inclusion in the first IVF/PGT-SR protocol, all of the female patients were tested for serum levels of day 2-3 AMH and FSH (Table A1). The COH was performed using the antagonist protocol with recombinant and/or urinary gonadotropins. The starting daily dose of gonadotropins ranged from 150 to $300 \mathrm{IU}$ and was chosen based on AMH 
level, antral follicle count and baseline FSH level. From the sixth day of stimulation, the FSH dosage was adjusted according to the number of growing follicles and their size. COCs were retrieved by transvaginal ultrasound-guided aspiration $36 \mathrm{~h}$ after the ovulation trigger administration. A total of 2020 COCs were retrieved in 137 IVF cycles analyzed in this study.

\subsection{Statistical Analysis}

The statistical analysis was performed using The R Project for Statistical Computing (https:/ / www.r-project.org). The inter-group comparison of the patients' age was performed using the Kruskal-Wallis test. The median numbers of COCs were compared with Mood's median test. The comparison of the number of COCs between the female reciprocal and Robertsonian translocation carriers $<35$ years of age and between their counterparts $\geq 35$ years of age was carried out using the Mann-Whitney $U$ test. The correlations between the number of COCs and the patients' age and between the number of COCs and the serum AMH/FSH levels were measured using Spearman's rank correlation coefficient. The $\alpha$-level was set at 0.05 .

\subsection{Ethical Issues}

The study was approved by the Ethics Committee of the D.O. Ott Research Institute of Obstetrics, Gynecology and Reproductology. All the patients gave written informed consent to the use of their medical records in the study. The study was conducted in accordance with the Declaration of Helsinki.

\section{Results and Discussion}

Due to a high probability of unbalanced gametes, carriers of balanced translocations have a high risk of infertility, pregnancy loss and the birth of a child with a chromosomal pathology $[3,11]$. For that reason, should such patients resort to IVF/PGT-SR, it is critical to obtain a sufficient number of oocytes to select the genetically balanced embryos suitable for uterine transfer. Due to a limited number of relevant studies and certain contradictions in their findings [12-14], the question of the impact of translocations on oocyte retrieval remains open. In this study, we checked whether female reciprocal and Robertsonian translocation carriers are at risk of a low number of $\mathrm{COCs}$ retrieved after $\mathrm{COH}$ and whether the number of COCs correlates with the woman's age and the serum AMH and FSH levels.

In medical literature, advanced maternal age has been consistently defined as $\geq 35$ years of age. Women aged over 35 years have a dramatically increased risk of aneuploid embryos resulting in miscarriage, stillbirth and offspring with chromosomal pathology [15-17]. The dominant reason for this is an elevated probability of meiotic errors in oogenesis and a production of karyotypically abnormal oocytes as a result, both in $46, \mathrm{XX}$ women and in translocation carriers [18]. Therefore, we used an age of 35 years as a cutoff between the young and old age group.

The female patients from the studied couples were subcategorized into six subgroups by age ( $<35$ and $\geq 35$ years of age) and presence of a chromosomal rearrangement (female carriers of a Robertsonian translocation, female carriers of a reciprocal translocation and karyotypically normal partners of male translocation carriers). The subgroups of patients within the groups aged $<35$ and $\geq 35$ years were checked for age-matching. No statistically significant difference was detected either among the subgroups of reciprocal and Robertsonian female translocation carriers and 46 , XX patients aged $<35$ years (KruskalWallis rank sum statistic $\mathrm{H}=0.66979, p=0.7154$; the distribution of $\mathrm{H}$ approximated by chi-squared distribution with $\mathrm{df}=2$ ) or among the subgroups of their counterparts aged $\geq 35$ years (Kruskal-Wallis rank sum statistic $\mathrm{H}=0.82567, p=0.6618$; the distribution of $\mathrm{H}$ approximated by chi-squared distribution with $\mathrm{df}=2$ ).

We compared the median numbers of COCs retrieved after $\mathrm{COH}$ in IVF/PGT-SR cycles in the above-described six subgroups of women (Figure 1). For each subgroup, we also calculated the interquartile range that reflected the variability of values within 
the subgroup. The median number of COCs varied from nine to 16 across the subgroups. This number of COCs is categorized as optimal (from 10 to 15), with a suboptimal number varying from four to nine COCs [19]. The highest variability was recorded in the subgroup of female reciprocal translocation carriers aged $<35$ years (an interquartile range of 16) and the lowest one in the subgroup of Robertsonian translocation carriers aged $\geq 35$ years (an interquartile range of 5). Regardless of a certain decrease in the medians in female translocation carriers $\geq 35$ years of age, the inter-group comparison of the medians showed no statistically significant difference (Mood's median test, chi-squared $=11.054, \mathrm{df}=7$, $p=0.1363$ ). Thus, the younger- and the older-age subgroups of both the female translocation carriers and the karyotypically normal partners of male translocation carriers produced an equal median number of COCs that is categorized as optimal. We have therefore concluded that the presence of a balanced translocation per se has no impact on the $\mathrm{COH}$ outcome and that the IVF/PGT-SR cycle with own gametes is a procedure of choice for female balanced translocation carriers.

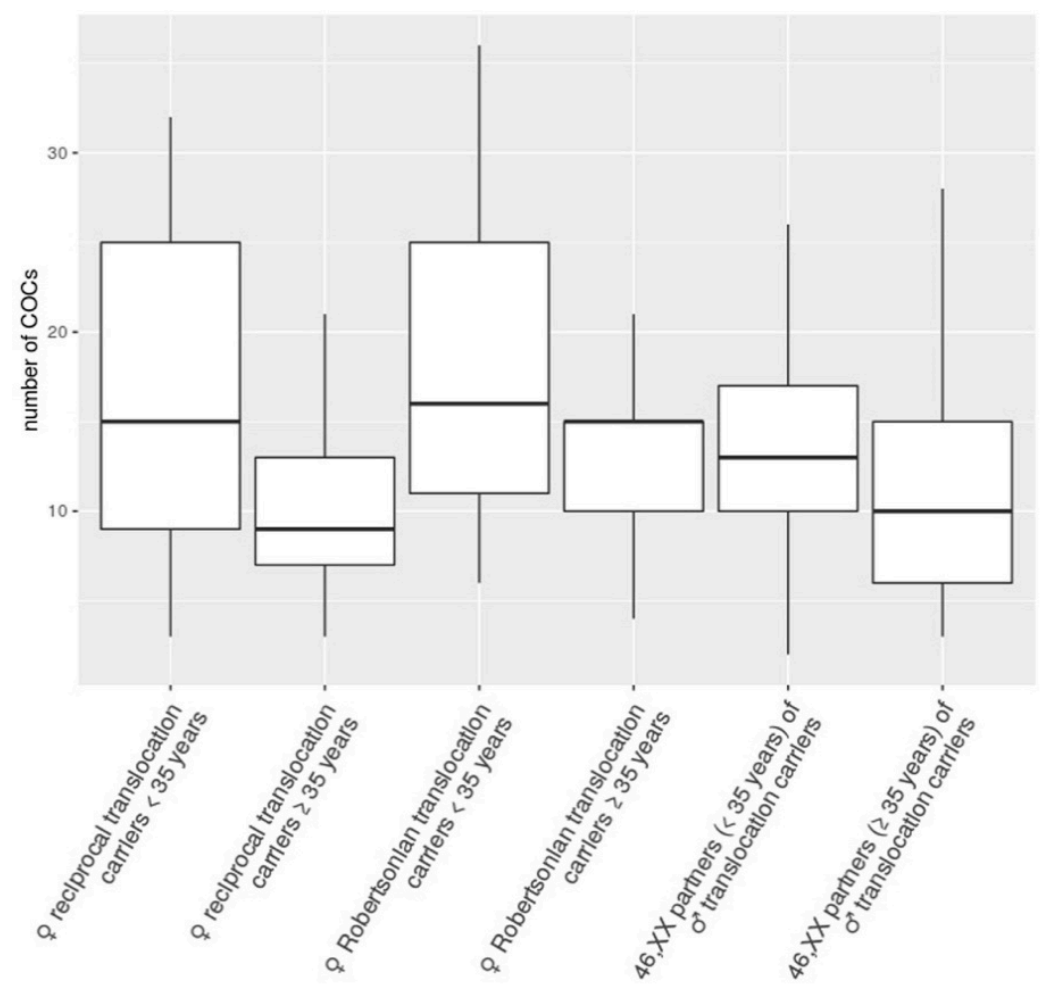

Figure 1. Box plot of the number of cumulus-oocyte complexes (COCs) retrieved after controlled ovarian hyperstimulation in six subgroups of women subcategorized by age ( $<35$ and $\geq 35$ years) and presence of a chromosomal rearrangement (female carriers of a Robertsonian translocation, female carriers of a reciprocal translocation and karyotypically normal partners of male translocation carriers). The lower whisker represents the smallest observation greater than or equal to the lower hinge-1.5 $\times \mathrm{IQR}$; the lower hinge represents the $25 \%$ quantile; the line through the middle region of the box represents the median, 50\% quantile; the upper hinge represents the $75 \%$ quantile; the upper whisker represents the largest observation less than or equal to the upper hinge $+1.5 \times$ IQR. The inter-group comparison of the medians showed no statistically significant difference (Mood's median test, chi-squared $=11.054, \mathrm{df}=7, p=0.1363$ ).

In the literature, the question of ovarian response to $\mathrm{COH}$ in female carriers of balanced translocations remains controversial, which is most likely explained by different approaches used by the authors. In the study by Chen et al., who applied up to 450 IU of gonadotropin for stimulation and used serum level of E2 on the day of hCG administration as an indicator of ovarian response, the proportion of very poor responders was significantly higher in the female carriers compared with the partners of male carri- 
ers [12]. D'Ippolito et al. reported retrieval of two and one mature oocytes in a female $t(1 ; 11)$ carrier who underwent two ovarian stimulations with high doses of gonadotropins (300 and $400 \mathrm{IU}$ ) [20]. The assessment of the ovarian response by follicular output rate (FORT, ratio between the pre-ovulatory follicle count on day of hCG $\times 100 /$ antral follicle count) revealed poor response in female translocation carriers [14]. The abovementioned results may be associated with alterations of molecular signaling in granulosa cells due to a genetic defect caused by translocation-specific breakpoints [20] and diminished antral follicle sensitivity to FSH [14]. In the studies by Dechanet et al. and Keymolen et al., optimal numbers of COCs were retrieved in female translocation carriers who underwent standard protocols of $\mathrm{COH}$ with standard doses of FSH $[13,21]$ which is consistent with our results. However, considering the existing controversy, we have decided to check the possible associations of the oocyte retrieval outcomes in female translocation carriers with the age, type of translocation and the ovarian reserve markers (the serum AMH and FSH levels).

Using correlation analysis, we checked the strength and the direction of the relationship between the number of COCs and the woman's age in three groups: female reciprocal translocation carriers, female Robertsonian translocation carriers and karyotypically normal partners of male translocation carriers (Figure 2). In all of the groups, the number of COCs correlated negatively with the woman's age. However, the correlation reached significance only in the translocation carriers, both reciprocal ( $\rho=-0.39$, $p=0.0062)$ and Robertsonian $(\rho=-0.37, p=0.039)$. In the karyotypically normal women, the correlation was not statistically significant $(\rho=-0.13, p=0.34)$. Thus, it is in female carriers of balanced translocations that age is a significant predictor of the number of oocytes retrieved after $\mathrm{COH}$. It is likely that age-dependent deterioration of the biological control of the physiological and biochemical processes involved in oocyte maturation is enhanced by the presence of chromosomal rearrangement in female translocation carriers. During oogenesis, the germline cells undergo several quality control checkpoints to initiate apoptosis of abnormal cells including those with genetic defects. As translocation carriers have an increased probability to produce chromosomally unbalanced cells, they are at higher risk of drastically depleted overall oocyte production with age than karyotypically normal women.
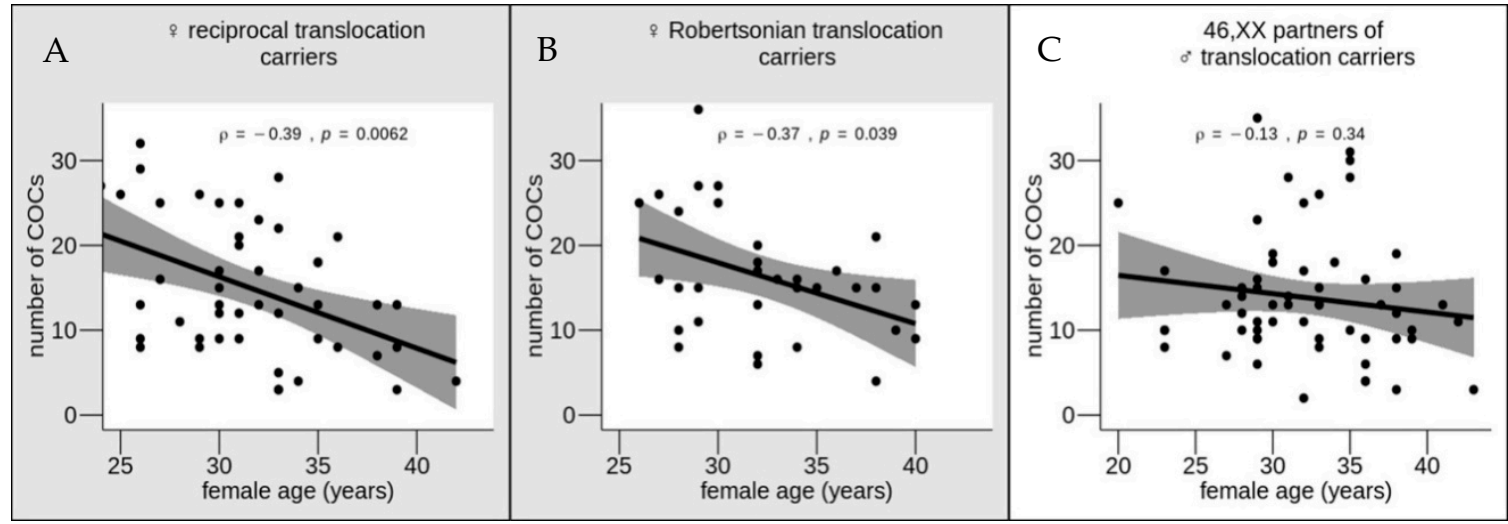

Figure 2. Correlations between the number of cumulus-oocyte complexes (COCs) retrieved after controlled ovarian hyperstimulation and woman's age in the groups of female reciprocal (A) and Robertsonian (B) translocation carriers and karyotypically normal partners of male translocation carriers (C); Table A1. The statistically significant correlations are shaded in gray ( $p<0.05$, Spearman test).

At the third stage of the study, we compared the possible effects of reciprocal and Robertsonian translocations on the number of oocytes retrieved from female translocation carriers. Using the Mann-Whitney $\mathrm{U}$ test, we compared the number of COCs between the female reciprocal and Robertsonian translocation carriers aged $<35$ years and between their counterparts aged $\geq 35$ years. No significant difference was detected between recip- 
rocal and Robertsonian translocation carriers aged either $<35$ years $(\mathrm{U}=364, p=0.5452)$ or $\geq 35$ years $(\mathrm{U}=40, p=0.3344$; Figure 3$)$. Thus, the translocation type-reciprocal or Robertsonian-does not have a significant impact on the number of oocytes retrieved after $\mathrm{COH}$ from female balanced translocation carriers.

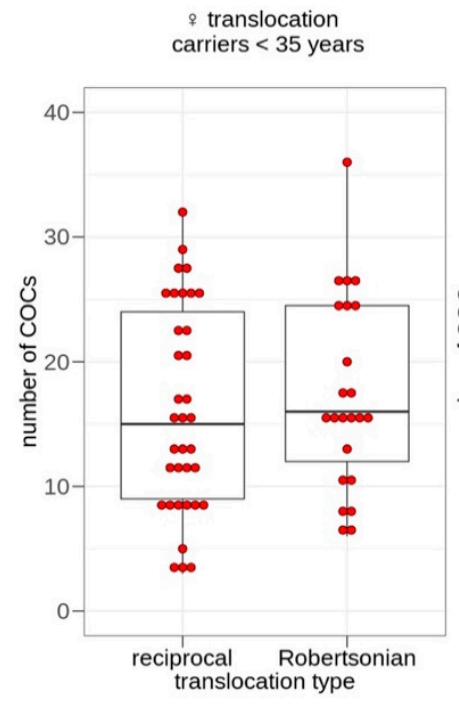

A

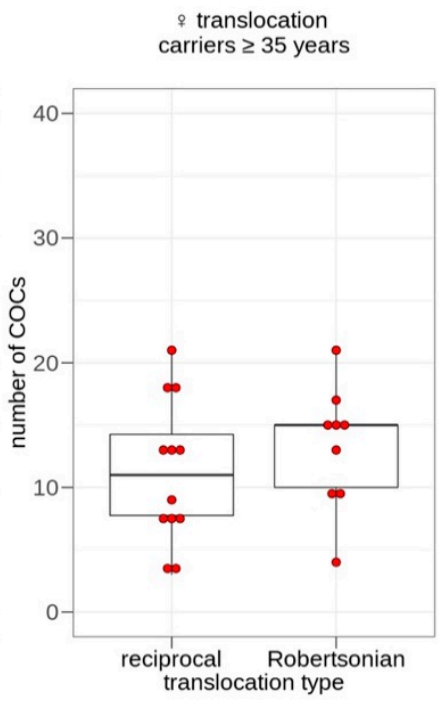

B

Figure 3. Box plots of the number of cumulus-oocyte complexes (COCs) retrieved after controlled ovarian hyperstimulation in female translocation carriers aged $<35$ (A) and $\geq 35$ (B) years. The lower whisker represents the smallest observation greater than or equal to the lower hinge $-1.5 \times$ IQR; the lower hinge represents the $25 \%$ quantile; the line through the box represents the median, $50 \%$ quantile; the upper hinge represents the $75 \%$ quantile; the upper whisker represents the largest observation less than or equal to the upper hinge $+1.5 \times \mathrm{IQR}$. No significant difference between the subgroups of female reciprocal and Robertsonian translocation carriers either $<35$ (A) or $\geq 35$ (B) years of age was detected (Mann-Whitney $\mathrm{U}$ test, $\mathrm{U}=364, p=0.5452$ and $\mathrm{U}=40, p=0.3344$, respectively).

Next, we analyzed the possible correlation between the serum AMH and FSH levels and the number of oocytes retrieved after $\mathrm{COH}$ from female translocation carriers. The serum AMH and FSH levels are considered to be the ovarian reserve markers. AMH is expressed in granulosa cells of preantral and small antral follicles, i.e., during the growth stage. When the growing follicles reach larger size, AMH expression diminishes and stops once FSH-dependent selection for dominance occurs [22]. Thus, AMH has an important role in regulating the number of growing follicles and may be involved in the determination of the good quality follicles to undergo selection for ovulation or poor quality follicles to be removed through atresia [23]. As the serum AMH and FSH levels in our study were tested in each woman once (before the inclusion in the first IVF/PGT-SR protocol), data from a total of 100 IVF/PGT-SR cycles were initially included in the analysis.

Using the Spearman test, we performed a correlation analysis of the serum AMH level and the number of COCs in six subgroups of women subcategorized by age $(<35$ or $\geq 35$ years) and presence of a chromosomal rearrangement (female carriers of a Robertsonian translocation, female carriers of a reciprocal translocation and karyotypically normal partners of male translocation carriers; Figure 4). Six women were excluded from the analysis because their AMH level was equal to or exceeded $15 \mathrm{ng} / \mathrm{mL}$ : two female reciprocal translocation carriers aged $<35$ years, one female Robertsonian translocation carrier aged $\geq 35$ years, one karyotypically normal partner of a male translocation carrier aged $<35$ years and two karyotypically normal partners (aged $\geq 35$ years) of male translocation carriers. 


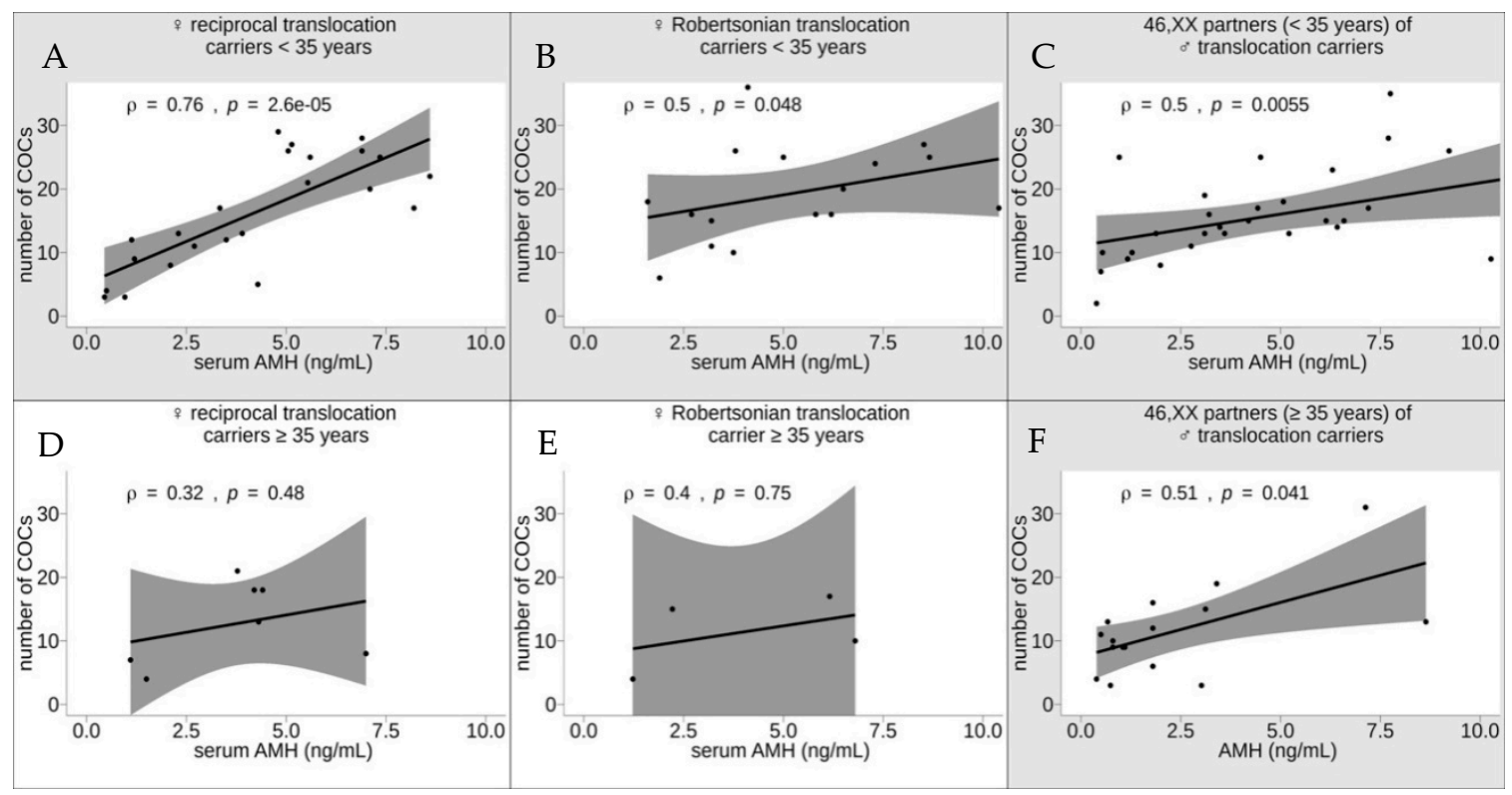

Figure 4. The correlations between the serum anti-Müllerian hormone (AMH) levels and the number of cumulus-oocyte complexes (COCs) retrieved after controlled ovarian hyperstimulation in six subgroups of women subcategorized by age ( $<35$ (A-C) and $\geq 35$ (D-F) years) and presence of a chromosomal rearrangement (female carriers of a reciprocal translocation (A,D), female carriers of a Robertsonian translocation (B,E) and karyotypically normal partners of male translocation carriers $(\mathbf{C}, \mathbf{F}))$. The statistically significant correlations are shaded in gray $(p<0.05$, Spearman test).

The strongest positive correlation between the number of COCs and the serum AMH level was detected in the subgroup of female reciprocal translocation carriers aged $<35$ years $\left(\rho=0.76, p=2.6 \times 10^{-5}\right)$. The subgroups of female Robertsonian translocation carriers aged $<35$ years and karyotypically normal partners (aged $<35$ years) of male translocation carriers showed correlations of similar strength $(\rho=0.5, p=0.048$ and $\rho=0.5, p=0.0055$, respectively). No significant correlation was detected in either reciprocal $(\rho=0.32, p=0.38)$ or Robertsonian $(\rho=0.4, p=0.75)$ translocation carriers aged $\geq 35$ years. However, to further confirm this finding, a larger group of patients needs to be tested. The subgroup of karyotypically normal women aged $\geq 35$ years, however, showed a rather strong positive correlation ( $\rho=0.51, p=0.041$; Figure 4$)$. Thus, the serum AMH level strongly predicts the number of $\mathrm{COCs}$ retrieved after $\mathrm{COH}$ from younger female reciprocal translocation carriers, whereas in female Robertsonian translocation carriers aged $<35$ years and in karyotypically normal women both $<35$ and $\geq 35$ years of age, this indicator is less sensitive.

The possible explanation of these results likely comes from a negative selection of unbalanced germline cells, which are produced at high incidence in translocation carriers [3]. Due to apoptosis of a part of unbalanced gametes, the translocation carriers may have a decreased follicle pool compared to karyotypically normal women. However, at the younger age, the follicle pool is not depleted significantly, and high AMH level plays an important role in selection of the dominant follicle. In the older age translocation carriers, the role of AMH is much less pronounced as they have depleted pool of oogenic cells and limited options for choice of the good quality dominant follicles.

We performed correlation analysis of the serum FSH level and the number of COCs in the same subgroups of women (Figure 5). Two female Robertsonian translocation carriers were excluded from the analysis because of a significant deviation of their serum FSH level $(0.27$ and $9.32 \mathrm{mlU} / \mathrm{mL})$. A significant strong negative correlation between the serum FSH level and the number of COCs was detected only in the subgroup of female Robertsonian translocation carriers aged $<35$ years $(\rho=-0.66, p=0.01)$. Why this correlation is present only in young Robertsonian but not reciprocal translocation carriers is an open and very intriguing question. Further studies will probably shed light on the biological mechanisms underlying this association. In the rest of the analyzed subgroups, 
the serum FSH level had no impact on the number of COCs retrieved after $\mathrm{COH}$ (Figure 5); however, the number of cases with translocation carriers aged $\geq 35$ years was too small to provide meaningful inferences. The increased serum FSH level can, therefore, indicate poor responders to $\mathrm{COH}$ only among young female Robertsonian translocation carriers.

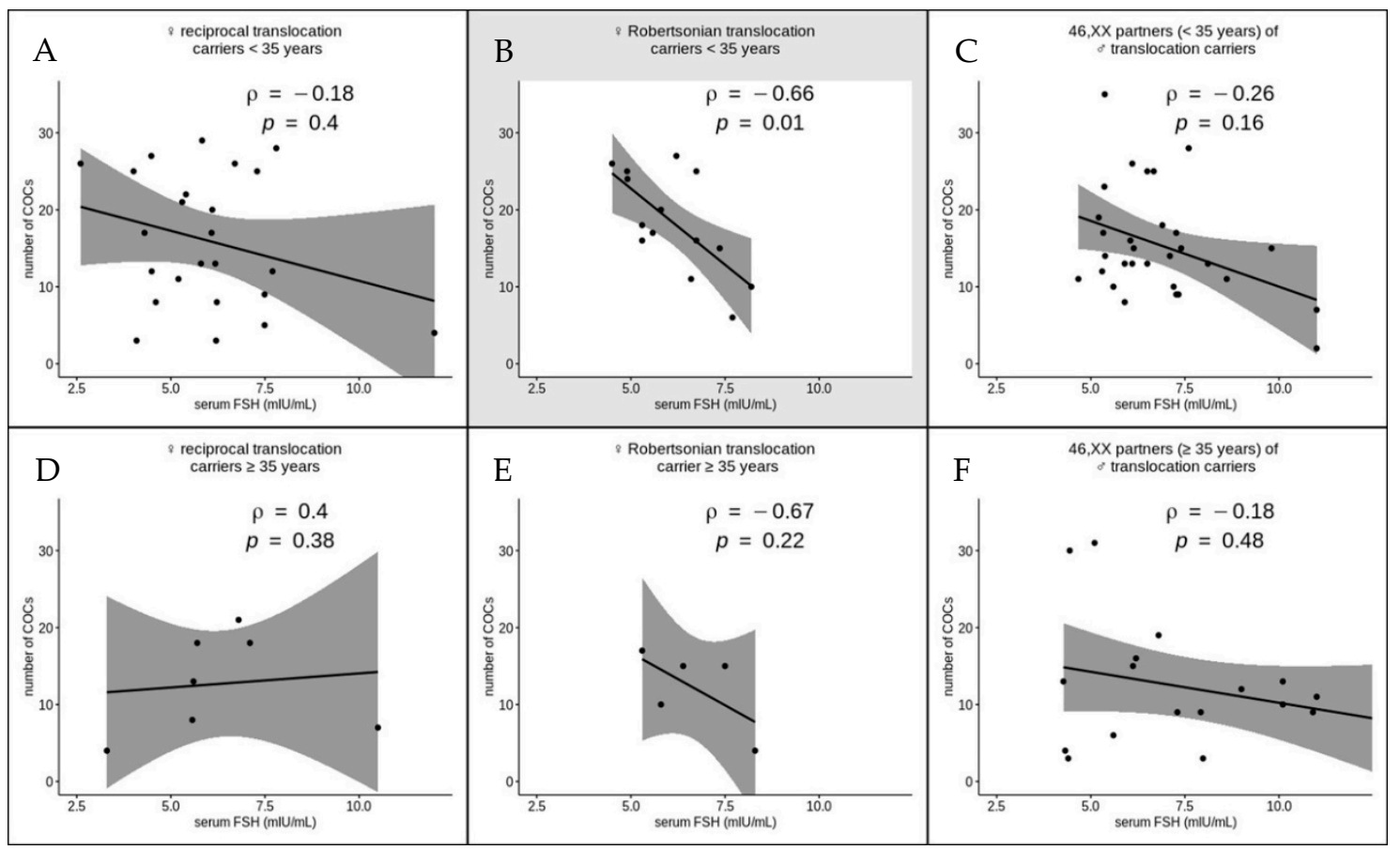

Figure 5. The correlations between the serum follicle-stimulating hormone (FSH) levels and the number of cumulus-oocyte complexes (COCs) retrieved after controlled ovarian hyperstimulation in six subgroups of women subcategorized by age ( $<35$ (A-C) and $\geq 35$ (D-F) years) and presence of a chromosomal rearrangement (female carriers of a reciprocal translocation (A,D), female carriers of a Robertsonian translocation (B,E) and karyotypically normal partners of male translocation carriers $(\mathbf{C}, \mathbf{F}))$. The statistically significant correlations are shaded in gray $(p<0.05$, Spearman test).

Taken together, our results suggest that the prognosis of oocyte retrieval outcome in translocation carriers should first consider female age and then serum AMH and FSH levels.

\section{Conclusions}

Our study demonstrates that the presence of a balanced translocation in woman regardless of the translocation type-reciprocal or Robertsonian-does not decrease the number of COCs retrieved after COH during IVF/PGT-SR cycles. We therefore suggest that the use of IVF followed by PGT-SR in female translocation carriers appears to be practical and justified. It should be taken into consideration, however, that, should a patient undergo an IVF/PGT-SR cycle at an older reproductive age ( $\geq 35$ years of age), a balanced translocation, either Robertsonian or reciprocal, may still drastically increase the risk of a poor $\mathrm{COH}$ outcome. The response to $\mathrm{COH}$ in translocation carriers may not differ from that in 46,XX women. However, due to abnormal chromosome conjugation and increased probability of unbalanced gametes, some of which are removed through apoptosis, the depletion of the ovarian pool in translocation carriers progresses faster than in karyotypically normal women. This makes the age especially critical for oocyte retrieval outcome in balanced translocation carriers.

The serum AMH level may be regarded as the strong predictor of a good response to $\mathrm{COH}$ only in young ( $<35$ years of age) female reciprocal translocation carriers. The predictive value of the serum AMH level on oocyte retrieval is moderate in young female Robertsonian translocation carriers and karyotypically normal partners of male translocation carriers. In older female translocation carriers, the serum AMH level does not correlate 
with the number of retrieved oocytes and cannot be regarded as a significant predictor of the $\mathrm{COH}$ outcome. It is also necessary to consider that an increased serum FSH level has a negative predictive value of the number of oocytes only in the younger age group of Robertsonian translocation carriers.

The limitations of this study should be mentioned. The first one concerns heterogeneity of the group of reciprocal translocation carriers. Most reciprocal translocations are unique, thus potentially providing a variety of genetic defects caused by translocation breakpoints, which, in turn, may result in very individual effects on ovarian response to $\mathrm{COH}$ [20]. The second one is related to a small number of cases with translocation carriers aged $\geq 35$ years. Due to a high risk of reproductive failures, balanced translocation carriers usually have remarkable medical history and are karyotyped at a relatively young age. At genetic counseling, translocation carriers are strongly advised not to delay their reproductive attempts. These issues make the inclusion in the study of a large group of older age translocation carriers highly problematic.

To summarize, either a reciprocal or a Robertsonian chromosomal translocation per se does not increase the risk of a poor COH outcome in an IVF/PGT-SR cycle. The success of the procedure, however, is to a large extent determined by the woman's age being $<35$ years, the serum AMH level in younger female reciprocal translocation carriers and the serum FSH level in younger female Robertsonian translocation carriers.

Author Contributions: Conception and design of the study: I.Y.K., A.A.P., A.M.G., Y.V.S.; data acquisition: Y.V.S., I.D.M., E.M.K., E.A.L., M.A.I., E.M.F., O.A.E., O.G.C., L.I.P., V.S.D., O.E.T.; data analysis and interpretation: Y.V.S., A.A.P., I.Y.K., A.M.G.; manuscript drafting: Y.V.S., A.A.P., O.A.E.; critical revision of the manuscript for important intellectual content: I.Y.K., A.M.G. All the authors have approved the final version of the manuscript. All authors have read and agreed to the published version of the manuscript.

Funding: The research was funded by the Ministry of Science and Higher Education of the Russian Federation, Basic Research Programs AAAA-A19-119021290033-1 (cytogenetic studies) and AAAA-A19-119030490047-8 (reproductive studies). Mariia A. Ishchuk is a grantee of RF President Scholarship.

Institutional Review Board Statement: The study was conducted according to the guidelines of the Declaration of Helsinki, and approved by the Ethics Committee of the D.O. Ott Research Institute of Obstetrics, Gynecology and Reproductology (protocol No. 88, 8 December 2017).

Informed Consent Statement: Informed consent to the use of medical records was obtained from all subjects involved in the study.

Data Availability Statement: The raw datasets analyzed during the current study are present in the Table A1 (Appendix A).

Acknowledgments: The authors would like to thank Olga I. Dudkina and Ksenia O. Khudadyan for their helpful advice during the preparation of the manuscript.

Conflicts of Interest: The authors declare no conflict of interest. 


\section{Appendix A}

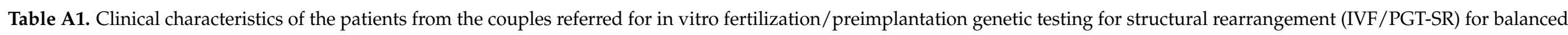
translocations.

\begin{tabular}{|c|c|c|c|c|c|c|c|}
\hline Couple \# & Carrier's Karyotype & Partner's Karyotype & Number of Cycles & Female Age, Years & $\begin{array}{c}\text { Number of } \\
\text { Cumulus-Oocyte } \\
\text { Complexes (COCs) }\end{array}$ & $\begin{array}{c}\text { Serum } \\
\text { Anti-Müllerian } \\
\text { Hormone (AMH), } \\
\text { ng/mL }\end{array}$ & $\begin{array}{c}\text { Serum } \\
\text { Follicle-Stimulating } \\
\begin{array}{c}\text { Hormone (FSH), } \\
\mathrm{mIU} / \mathrm{mL}\end{array}\end{array}$ \\
\hline 1 & $46, X X, t(1 ; 16)(p 31 ; q 21)$ & $46, X Y$ & 2 & 26 & 9 & & \\
\hline 2 & $46, \mathrm{XX}, \mathrm{t}(2 ; 17)(\mathrm{p} 21 ; \mathrm{p} 13)$ & $46, X Y$ & 1 & 31 & 9 & 1.2 & 7.49 \\
\hline \multirow{3}{*}{3} & \multirow{3}{*}{ 46,XX,t(10;15)(q22;q15) } & \multirow{3}{*}{$46, X Y$} & \multirow{3}{*}{3} & \multirow{2}{*}{33} & 5 & 4.29 & 7.49 \\
\hline & & & & & 12 & & \\
\hline & & & & 35 & 9 & & \\
\hline 4 & $46, X X, t(10 ; 18)(q 21 ; q 22)$ & $46, X Y$ & 1 & 31 & 12 & 3.5 & 4.49 \\
\hline 5 & $46, X X, t(2 ; 11)(p 13 ; q 21)$ & $46, X Y$ & 2 & 30 & 12 & 1.13 & 7.7 \\
\hline 6 & $46, X X, t(4 ; 12)(q 32 ; q 23)$ & $46, X Y$ & 1 & 33 & 3 & 0.96 & 6.2 \\
\hline \multirow{4}{*}{7} & \multirow{4}{*}{$46, X X, t(2 ; 16)(q 33 ; q 22)$} & \multirow{4}{*}{$46, X Y$} & \multirow{4}{*}{4} & 36 & 8 & 7 & 5.57 \\
\hline & & & & 38 & 13 & & \\
\hline & & & & \multirow{2}{*}{39} & 8 & & \\
\hline & & & & & 3 & & \\
\hline \multirow{2}{*}{8} & \multirow{2}{*}{$46, \mathrm{XX}, \mathrm{t}(3 ; 14)(\mathrm{q} 25 ; \mathrm{q} 11.2)$} & \multirow{2}{*}{$46, X Y$} & \multirow{2}{*}{2} & \multirow{2}{*}{29} & 8 & 18.75 & 6.22 \\
\hline & & & & & 9 & & \\
\hline 9 & $46, X X, t(4 ; 11)(q 22 ; q 24)$ & $46, X Y$ & 1 & 32 & 13 & 3.9 & 6.18 \\
\hline
\end{tabular}


Table A1. Cont.

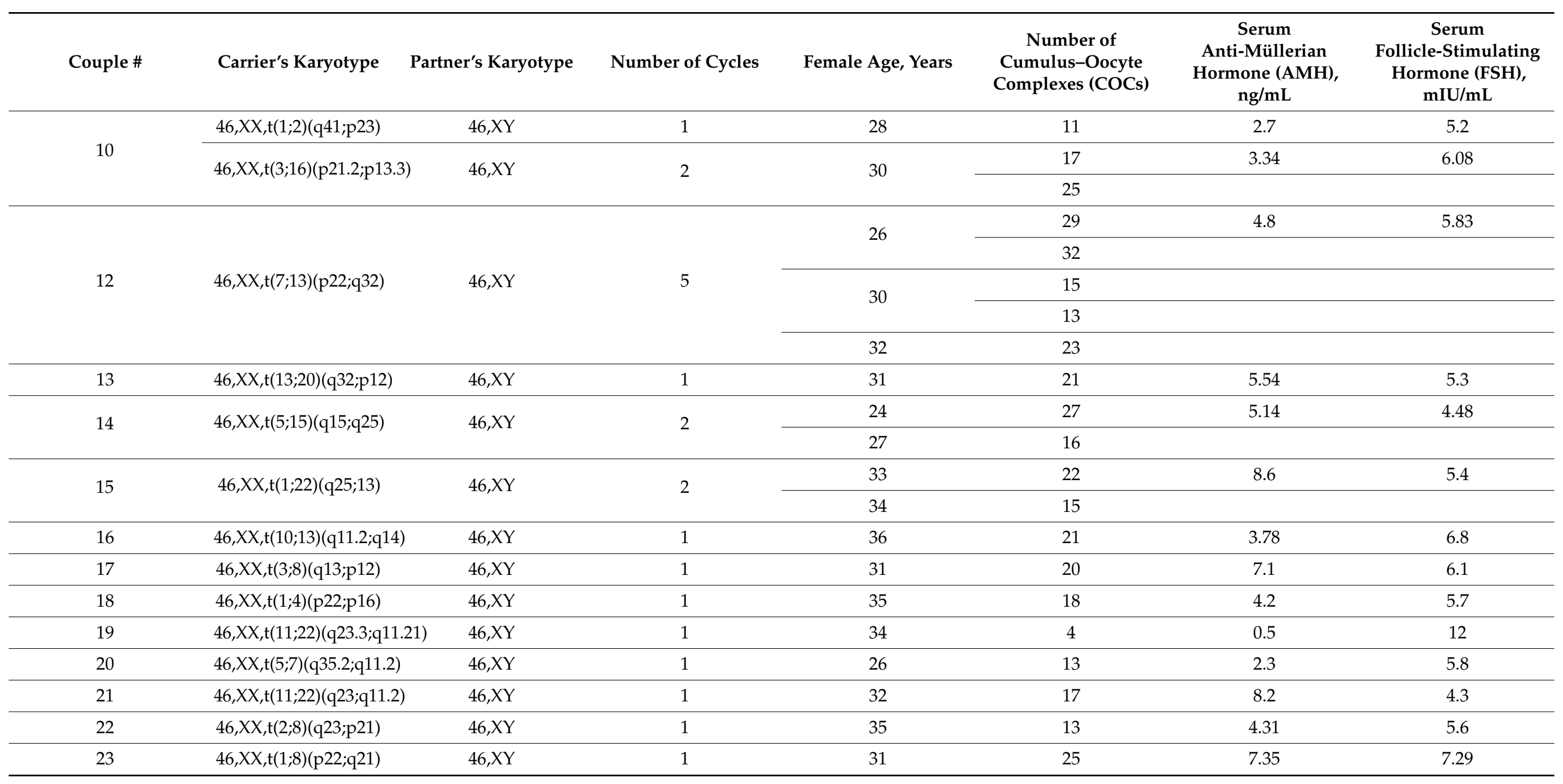


Table A1. Cont.

\begin{tabular}{|c|c|c|c|c|c|c|c|}
\hline Couple \# & Carrier's Karyotype & Partner's Karyotype & Number of Cycles & Female Age, Years & $\begin{array}{c}\text { Number of } \\
\text { Cumulus-Oocyte } \\
\text { Complexes (COCs) }\end{array}$ & $\begin{array}{c}\text { Serum } \\
\text { Anti-Müllerian } \\
\text { Hormone (AMH), } \\
\text { ng/mL }\end{array}$ & $\begin{array}{c}\text { Serum } \\
\text { Follicle-Stimulating } \\
\text { Hormone (FSH), } \\
\text { mIU/mL }\end{array}$ \\
\hline 25 & $46, \mathrm{XX}, \mathrm{t}(4 ; 13)(\mathrm{p} 16.3 ; \mathrm{q} 22.3)$ & $46, X Y$ & 1 & 27 & 25 & 5.6 & 4.01 \\
\hline \multirow{2}{*}{26} & \multirow{2}{*}{$46, X X, t(1 ; 19)(p 13 ; q 13.1)$} & \multirow{2}{*}{$46, X Y$} & \multirow{2}{*}{2} & 38 & 7 & 1.1 & 10.5 \\
\hline & & & & 39 & 13 & & \\
\hline 27 & $46, X X, t(9 ; 11)(q 13 ; q 13)$ & $46, X Y$ & 1 & 33 & 3 & 0.45 & 4.09 \\
\hline 28 & $46, X X, t(6 ; 8)(q 12 ; q 11.23)$ & $46, X Y$ & 1 & 29 & 26 & 6.9 & 2.6 \\
\hline 29 & $46, X X, t(5 ; 14)(\mathrm{p} 15 ; \mathrm{q} 24)$ & $46, X Y$ & 1 & 42 & 4 & 1.5 & 3.3 \\
\hline 30 & $46, X X, t(9 ; 10)(p 24 ; q 22)$ & $46, X Y$ & 1 & 25 & 26 & 5.05 & 6.7 \\
\hline 31 & $46, X X, t(1 ; 5)(p 34 ; q 13)$ & $46, X Y$ & 1 & 33 & 28 & 6.9 & 7.8 \\
\hline 32 & $46, X Y, t(1 ; 2)(q 41 ; q 34)$ & $46, X X$ & 1 & 29 & 15 & 6.14 & 6.15 \\
\hline 34 & $\begin{array}{c}46, \mathrm{XY} \\
\mathrm{t}(8 ; 18)(\mathrm{q} 12 ; \mathrm{p} 11.2)\end{array}$ & $46, X X$ & 1 & 30 & 19 & 3.1 & 5.21 \\
\hline 35 & $\begin{array}{c}46, X Y \\
\mathrm{t}(7 ; 11)(\mathrm{q} 32 ; \mathrm{q} 21)\end{array}$ & $46, X X$ & 1 & 37 & 13 & 8.64 & 4.27 \\
\hline 36 & $46, \mathrm{XY}, \mathrm{t}(10 ; 21)(\mathrm{q} 11.2 ; \mathrm{q} 21)$ & $46, X X$ & 1 & 30 & 11 & 11.4 & 4.67 \\
\hline 37 & $46, \mathrm{XY}, \mathrm{t}(16 ; 19)(\mathrm{p} 11.2 ; \mathrm{p} 13.1)$ & $46, X X$ & 1 & 38 & 19 & 3.4 & 6.8 \\
\hline \multirow{2}{*}{38} & \multirow{2}{*}{$46, X Y, t(7 ; 21)(q 32 ; q 21)$} & \multirow{2}{*}{$46, X X$} & \multirow{2}{*}{2} & \multirow{2}{*}{39} & 9 & 1.1 & 7.3 \\
\hline & & & & & 10 & & - \\
\hline 39 & 46,XY,t(5;11)(p15;q23) & $46, X X$ & 1 & 33 & 13 & 3.6 & 6.5 \\
\hline 40 & $46, \mathrm{XY}, \mathrm{t}(16 ; 19)(\mathrm{p} 11.2 ; \mathrm{p} 13.1)$ & $46, X X$ & 1 & 38 & 15 & 3.12 & 6.12 \\
\hline
\end{tabular}


Table A1. Cont.

\begin{tabular}{|c|c|c|c|c|c|c|c|}
\hline Couple \# & Carrier's Karyotype & Partner's Karyotype & Number of Cycles & Female Age, Years & $\begin{array}{c}\text { Number of } \\
\text { Cumulus-Oocyte } \\
\text { Complexes (COCs) }\end{array}$ & $\begin{array}{c}\text { Serum } \\
\text { Anti-Müllerian } \\
\text { Hormone (AMH), } \\
\text { ng/mL }\end{array}$ & $\begin{array}{c}\text { Serum } \\
\text { Follicle-Stimulating } \\
\text { Hormone (FSH), } \\
\text { mIU/mL }\end{array}$ \\
\hline \multirow{3}{*}{42} & \multirow{3}{*}{$46, X Y, t(3 ; 6)(q 26.2 ; q 23)$} & \multirow{3}{*}{$46, X X$} & \multirow{3}{*}{3} & 32 & 25 & 4.5 & 6.5 \\
\hline & & & & 34 & 18 & & \\
\hline & & & & 35 & 28 & & \\
\hline \multirow{2}{*}{43} & \multirow{2}{*}{$46, X Y, t(11 ; 20)(q 21 ; q 13)$} & \multirow{2}{*}{$46, X X$} & \multirow{2}{*}{2} & \multirow{2}{*}{33} & 26 & 9.22 & 6.1 \\
\hline & & & & & 9 & & \\
\hline 44 & $46, X Y, t(9 ; 15)(q 12 ; q 26)$ & $46, X X$ & 1 & 28 & 12 & 18.3 & 5.3 \\
\hline 45 & $46, X Y, t(7 ; 11)(q 22 ; q 23)$ & $46, X X$ & 1 & 38 & 3 & 0.74 & 7.98 \\
\hline 46 & $46, X Y, t(3 ; 8)(p 25 ; q 12)$ & $46, X X$ & 1 & 23 & 17 & 7.2 & 5.33 \\
\hline 47 & $\begin{array}{c}46, X Y, t(3 ; 13)(\mathrm{p} 21.2- \\
\text { p21.3;q32) }\end{array}$ & $46, X X$ & 1 & 38 & 12 & 1.8 & 9 \\
\hline 48 & 46,XY,t(7;11)(q31.2;p14) & $46, X X$ & 2 & 29 & 10 & & \\
\hline \multirow{2}{*}{49} & \multirow{2}{*}{$46, \mathrm{XY}, \mathrm{t}(1 ; 8)(\mathrm{q} 42.1 ; \mathrm{q} 24.2)$} & \multirow{2}{*}{$46, X X$} & \multirow{2}{*}{2} & 29 & 9 & 10.27 & 7.27 \\
\hline & & & & 31 & 13 & & \\
\hline 50 & $46, X Y, t(6 ; 11)(p 21.3 ; q 13)$ & $46, X X$ & 1 & 35 & 31 & 7.13 & 5.1 \\
\hline 51 & 46,XY,t(1;4)(q32;p16) & $46, X X$ & 1 & 36 & 6 & 1.8 & 5.6 \\
\hline 52 & $46, X Y, t(7 ; 14)(q 21.3 ; q 31.2)$ & $46, X X$ & 1 & 29 & 35 & 7.75 & 5.37 \\
\hline 53 & $46, X Y, t(3 ; 6)(q 25 ; p 21)$ & $46, X X$ & 1 & 29 & 11 & 2.76 & 8.61 \\
\hline 54 & $46, X Y, t(6 ; 16)(q 21 ; q 24)$ & $46, X X$ & 1 & 43 & 3 & 3.02 & 4.4 \\
\hline 55 & $46, \mathrm{XY}, \mathrm{t}(11 ; 22)(\mathrm{q} 23.3 ; \mathrm{q} 11.2)$ & $46, X X$ & 1 & 30 & 18 & 5.07 & 6.9 \\
\hline 56 & $46, X Y, t(1 ; 17)(p 13 ; p 11.2)$ & $46, X X$ & 1 & 28 & 10 & 1.28 & 7.2 \\
\hline
\end{tabular}


Table A1. Cont.

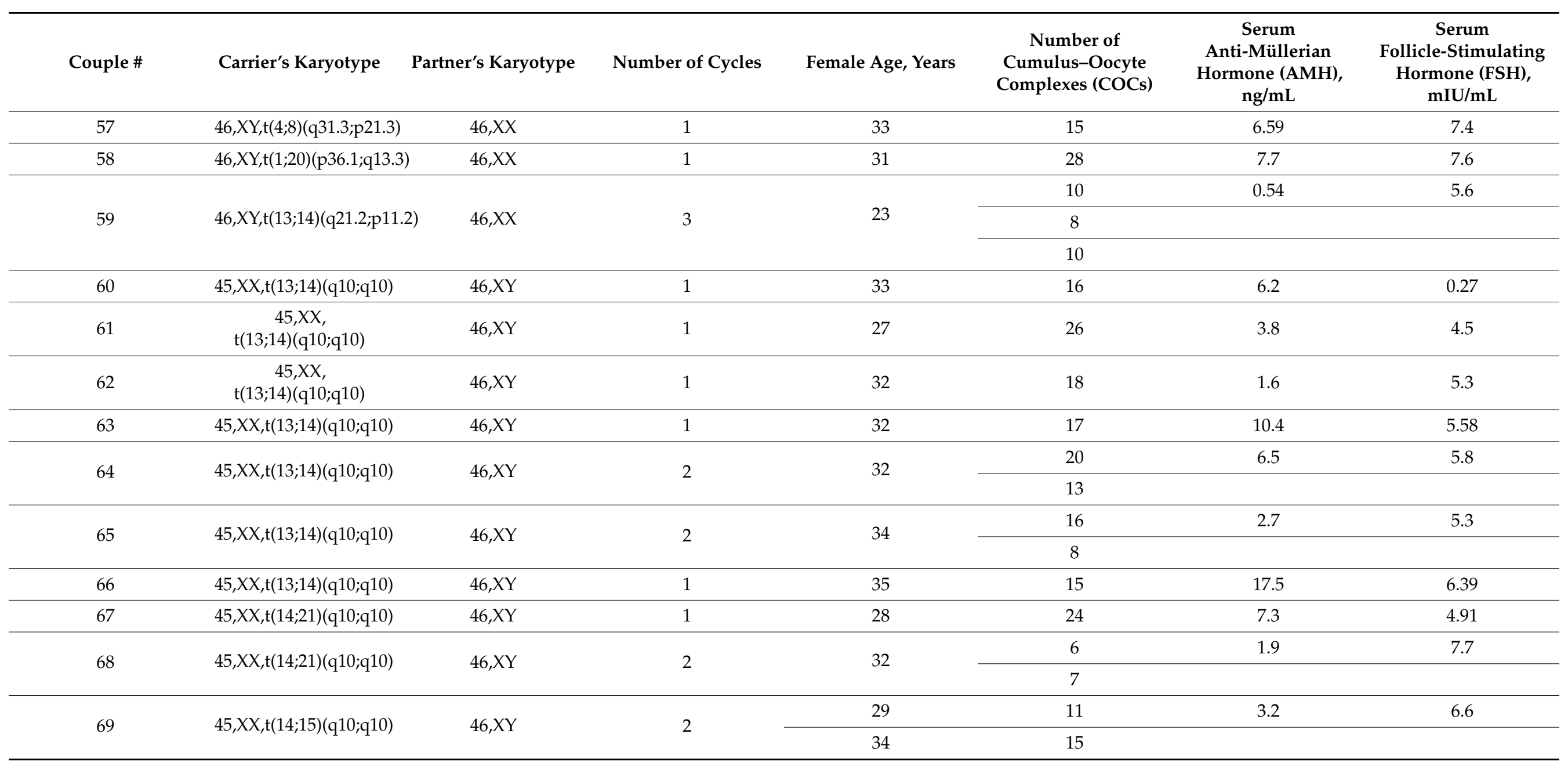


Table A1. Cont.

\begin{tabular}{|c|c|c|c|c|c|c|c|}
\hline Couple \# & Carrier's Karyotype & Partner's Karyotype & Number of Cycles & Female Age, Years & $\begin{array}{c}\text { Number of } \\
\text { Cumulus-Oocyte } \\
\text { Complexes (COCs) }\end{array}$ & $\begin{array}{c}\text { Serum } \\
\text { Anti-Müllerian } \\
\text { Hormone (AMH), } \\
\text { ng/mL }\end{array}$ & $\begin{array}{c}\text { Serum } \\
\text { Follicle-Stimulating } \\
\text { Hormone (FSH), } \\
\text { mIU/mL }\end{array}$ \\
\hline \multirow[t]{2}{*}{70} & \multirow[t]{2}{*}{ 45,XX,t(13;14)(q10;q10) } & \multirow[t]{2}{*}{$46, X Y$} & \multirow[t]{2}{*}{3} & 29 & 15 & & \\
\hline & & & & 30 & 27 & & \\
\hline 71 & $45, X X, t(13 ; 14)(q 10 ; q 10)$ & $46, X Y$ & 1 & 28 & 15 & 3.2 & 7.36 \\
\hline 72 & $45, \mathrm{XX}, \mathrm{t}(13 ; 14)(\mathrm{q} 10 ; \mathrm{q} 10)$ & $46, X Y$ & 1 & 27 & 16 & 5.81 & 6.74 \\
\hline 73 & $45, X X, t(13 ; 14)(q 10 ; q 10)$ & $46, X Y$ & 1 & 26 & 25 & 5 & 4.9 \\
\hline 74 & $45, \mathrm{XX}, \mathrm{t}(13 ; 14)(\mathrm{q} 10 ; \mathrm{q} 10)$ & $46, X Y$ & 1 & 29 & 36 & 4.11 & 9.32 \\
\hline \multirow{2}{*}{75} & \multirow{2}{*}{$45, \mathrm{XX}, \mathrm{t}(14 ; 22)(\mathrm{q} 10 ; \mathrm{q} 10)$} & $46, X Y$ & \multirow{2}{*}{2} & \multirow{2}{*}{28} & 10 & 3.75 & 8.2 \\
\hline & & $46, X Y$ & & & 8 & & \\
\hline \multirow{3}{*}{76} & \multirow{3}{*}{$45, \mathrm{XX}, \mathrm{t}(13 ; 14)(\mathrm{q} 10 ; \mathrm{q} 10)$} & \multirow{3}{*}{$46, X Y$} & \multirow{3}{*}{3} & 38 & 15 & 2.22 & 7.5 \\
\hline & & & & \multirow{2}{*}{40} & 13 & & \\
\hline & & & & & 9 & & \\
\hline \multirow{3}{*}{77} & \multirow{3}{*}{$45, X X, t(13 ; 14)(q 10 ; q 10)$} & \multirow{3}{*}{$46, X Y$} & \multirow{3}{*}{3} & 36 & 17 & 6.16 & 5.3 \\
\hline & & & & 37 & 15 & & \\
\hline & & & & 38 & 21 & & \\
\hline 78 & $45, X X, t(13 ; 14)(q 10 ; q 10)$ & $46, X Y$ & 1 & 38 & 4 & 1.23 & 8.3 \\
\hline 79 & $45, X X, t(14 ; 21)(q 10 ; q 10)$ & $46, X Y$ & 1 & 39 & 10 & 6.8 & 5.8 \\
\hline 80 & $45, X X, t(13 ; 14)(q 10 ; q 10)$ & $46, X Y$ & 1 & 30 & 25 & 8.66 & 6.74 \\
\hline 81 & 45,XY,t(14;21)(q10;q10) & $46, X X$ & 1 & 32 & 17 & 4.43 & 7.27 \\
\hline 82 & 45,XY,t(13,14)(q10;q10) & $46, X X$ & 1 & 28 & 14 & 6.42 & 5.38 \\
\hline \multirow{2}{*}{83} & \multirow{2}{*}{$45, \mathrm{XY}, \mathrm{t}(13 ; 14)(\mathrm{p} 11.2 ; \mathrm{p} 11.2)$} & \multirow{2}{*}{$46, X X$} & \multirow{2}{*}{2} & \multirow{2}{*}{29} & 9 & 1.17 & 7.33 \\
\hline & & & & & 6 & & \\
\hline
\end{tabular}


Table A1. Cont.

\begin{tabular}{|c|c|c|c|c|c|c|c|}
\hline Couple \# & Carrier's Karyotype & Partner's Karyotype & Number of Cycles & Female Age, Years & $\begin{array}{c}\text { Number of } \\
\text { Cumulus-Oocyte } \\
\text { Complexes (COCs) }\end{array}$ & $\begin{array}{c}\text { Serum } \\
\text { Anti-Müllerian } \\
\text { Hormone (AMH), } \\
\text { ng/mL }\end{array}$ & $\begin{array}{c}\text { Serum } \\
\text { Follicle-Stimulating } \\
\text { Hormone (FSH), } \\
\text { mIU/mL }\end{array}$ \\
\hline 85 & $45, \mathrm{XY}, \mathrm{t}(14 ; 15)(\mathrm{q} 10 ; \mathrm{q} 10)$ & $46, X X$ & 1 & 29 & 16 & 3.21 & 6.05 \\
\hline 86 & $45, \mathrm{XY}, \mathrm{t}(13 ; 14)(\mathrm{q} 10 ; \mathrm{q} 10)$ & $46, X X$ & 1 & 28 & 15 & 4.2 & 9.8 \\
\hline \multirow{2}{*}{87} & \multirow{2}{*}{$45, \mathrm{XY}, \mathrm{t}(14 ; 22)(\mathrm{q} 10 ; \mathrm{q} 10)$} & \multirow{2}{*}{$46, X X$} & \multirow{2}{*}{2} & 31 & 14 & 3.48 & 7.1 \\
\hline & & & & 32 & 11 & & \\
\hline 88 & $45, \mathrm{XY}, \mathrm{t}(14 ; 21)(\mathrm{q} 10 ; \mathrm{q} 10)$ & $46, X X$ & 1 & 30 & 13 & 1.88 & 8.11 \\
\hline 89 & $45, \mathrm{XY}, \mathrm{t}(13 ; 14)(\mathrm{q} 10 ; \mathrm{q} 10)$ & $46, X X$ & 1 & 29 & 23 & 6.3 & 5.36 \\
\hline 90 & $45, \mathrm{XY}, \mathrm{t}(14 ; 21)(\mathrm{q} 10 ; \mathrm{q} 10)$ & $46, X X$ & 1 & 38 & 9 & 0.8 & 10.9 \\
\hline 91 & $45, \mathrm{XY}, \mathrm{t}(14 ; 21)(\mathrm{q} 10 ; \mathrm{q} 10)$ & $46, X X$ & 1 & 35 & 10 & 0.8 & 10.1 \\
\hline 92 & 45,XY,(15;21)(q10;q10) & $46, X X$ & 1 & 41 & 13 & 0.67 & 10.1 \\
\hline 93 & $45, \mathrm{XY}, \mathrm{t}(13 ; 14)(\mathrm{q} 10 ; \mathrm{q} 10)$ & $46, X X$ & 1 & 42 & 11 & 0.5 & 11 \\
\hline 94 & $45, \mathrm{XY}, \mathrm{t}(13 ; 14)(\mathrm{q} 10 ; \mathrm{q} 10)$ & $46, X X$ & 1 & 20 & 25 & 0.96 & 6.67 \\
\hline 95 & $45, \mathrm{XY}, \mathrm{t}(13 ; 14)(\mathrm{q} 10 ; \mathrm{q} 10)$ & $46, X X$ & 1 & 36 & 4 & 0.39 & 11.5 \\
\hline 96 & $45, \mathrm{XY}, \mathrm{t}(13 ; 14)(\mathrm{q} 10 ; \mathrm{q} 10)$ & $46, X X$ & 1 & 33 & 8 & 1.99 & 5.9 \\
\hline 97 & $45, \mathrm{XY}, \mathrm{t}(13 ; 14)(\mathrm{q} 10 ; \mathrm{q} 10)$ & $46, X X$ & 1 & 36 & 4 & 17.33 & 4.32 \\
\hline 98 & $45, \mathrm{XY}, \mathrm{t}(13 ; 14)(\mathrm{q} 10 ; \mathrm{q} 10)$ & $46, X X$ & 1 & 27 & 7 & 0.5 & 11 \\
\hline 99 & $45, X Y(13 ; 14)(q 10 ; q 10)$ & $46, X X$ & 1 & 32 & 2 & 0.39 & 11 \\
\hline 100 & $45, X Y(13 ; 14)(q 10 ; q 10)$ & $46, X X$ & 1 & 35 & 30 & 15 & 4.44 \\
\hline
\end{tabular}




\section{References}

1. Shah, K.; Sivapalan, G.; Gibbons, N.; Tempest, H.; Griffin, D.K. The genetic basis of infertility. Reproduction 2003, 126, 13-25. [CrossRef] [PubMed]

2. Wilch, E.S.; Morton, C.C. Historical and clinical perspectives on chromosomal translocations. In Advances in Experimental Medicine and Biology; Zhang, Y., Ed.; Springer: New York, NY, USA, 2018; Volume 1044, pp. 1-14. [CrossRef]

3. Gardner, R.J.M.; Sutherland, G.; Shaffer, L. Chromosome Abnormalities and Genetic Counseling, 4th ed.; Oxford University Press: New York, NY, USA, 2012. [CrossRef]

4. Imudia, A.N.; Plosker, S. The Past, Present, and Future of Preimplantation Genetic Testing. Clin. Lab. Med. 2016, 36, 385-399. [CrossRef]

5. Kuliev, A.; Rechitsky, S. Preimplantation genetic testing: Current challenges and future prospects. Expert Rev. Mol. Diagn. 2017, 17, 1071-1088. [CrossRef] [PubMed]

6. Pendina, A.A.; Efimova, O.A.; Tikhonov, A.V.; Chiryaeva, O.G.; Fedorova, I.D.; Koltsova, A.S.; Krapivin, M.I.; Parfenyev, S.E.; Kuznetzova, T.V.; Baranov, V.S. Immunofluorescence Staining for Cytosine Modifications Like 5-Methylcytosine and Its Oxidative Derivatives and FISH. In Springer Protocols Handbooks; Liehr, T., Ed.; Springer: Berlin/Heidelberg, Germany, 2017 ; pp. 337-346. [CrossRef]

7. Grigorian, A.S.; Kruglyakov, P.V.; Taminkina, U.A.; Efimova, O.A.; Pendina, A.A.; Voskresenskaya, A.V.; Kuznetsova, T.V.; Polyntsev, D.G. Alterations of cytological and karyological profile of human mesenchymal stem cells during in vitro culturing. Bull. Exp. Biol. Med. 2010, 150, 125-130. [CrossRef] [PubMed]

8. Pendina, A.A.; Shilenkova, Y.V.; Talantova, O.E.; Efimova, O.A.; Chiryaeva, O.G.; Malysheva, O.V.; Dudkina, V.S.; Petrova, L.I.; Serebryakova, E.A.; Shabanova, E.S.; et al. Reproductive History of a Woman with 8p and 18p Genetic Imbalance and Minor Phenotypic Abnormalities. Front. Genet. 2019, 10, 1164. [CrossRef] [PubMed]

9. Puppo, I.L.; Saifitdinova, A.F.; Loginova, Y.A.; Kinunen, A.A.; Tonyan, Z.N.; Pastukhova, Y.R.; Leontyeva, O.A.; Kuznetsova, R.A.; Chiryaeva, O.G.; Pendina, A.A.; et al. Y/15 and Y/22 Derivative Chromosomes in Couples with Reproductive Failures: Algorithm of Preimplantation Genetic Testing and Specificity of Inheritance. Russ. J. Genet. 2020, 56, 488-495. [CrossRef]

10. Efimova, O.A.; Pendina, A.A.; Tikhonov, A.V.; Parfenyev, S.E.; Mekina, I.D.; Komarova, E.M.; Mazilina, M.A.; Daev, E.V.; Chiryaeva, O.G.; Galembo, I.A.; et al. Genome-wide 5-hydroxymethylcytosine patterns in human spermatogenesis are associated with semen quality. Oncotarget 2017, 8, 88294-88307. [CrossRef] [PubMed]

11. Morin, S.J.; Eccles, J.; Iturriaga, A.; Zimmerman, R.S. Translocations, inversions and other chromosome rearrangements. Fertil. Steril. 2017, 107, 19-26. [CrossRef] [PubMed]

12. Chen, S.H.; Escudero, T.; Cekleniak, N.A.; Sable, D.B.; Garrisi, G.; Munne, S. Patterns of ovarian response to gonadotropin stimulation in female carriers of balanced translocation. Fertil. Steril. 2005, 83, 1504-1509. [CrossRef] [PubMed]

13. Dechanet, C.; Castelli, C.; Reyftmann, L.; Hamamah, S.; Hedon, B.; Dechaud, H.; Anahory, T. Do female translocations influence the ovarian response pattern to controlled ovarian stimulation in preimplantation genetic diagnosis? Hum. Reprod. 2011, 26, 1232-1240. [CrossRef] [PubMed]

14. Mayeur, A.; Ahdad, N.; Hesters, L.; Grynberg, M.; Romana, S.; Sonigo, C.; Frydman, N. Does the prognosis after PGT for structural rearrangement differ between female and male translocation carriers? Reprod. Biomed. Online 2020, 40, 684-692. [CrossRef] [PubMed]

15. Franasiak, J.M.; Forman, E.J.; Hong, K.H.; Werner, M.D.; Upham, K.M.; Treff, N.R.; Scott, R.T., Jr. The nature of aneuploidy with increasing age of the female partner: A review of 15,169 consecutive trophectoderm biopsies evaluated with comprehensive chromosomal screening. Fertil. Steril. 2014, 101, 656-663.e1. [CrossRef] [PubMed]

16. Pendina, A.A.; Efimova, O.A.; Chiryaeva, O.G.; Tikhonov, A.V.; Petrova, L.I.; Dudkina, V.S.; Sadik, N.A.; Fedorova, I.D.; Galembo, I.A.; Kuznetzova, T.V.; et al. A comparative cytogenetic study of miscarriages after IVF and natural conception in women aged under and over 35 years. J. Assist. Reprod. Genet. 2014, 31, 149-155. [CrossRef] [PubMed]

17. Sauer, M.V. Reproduction at an advanced maternal age and maternal health. Fertil. Steril. 2015, 103, 1136-1143. [CrossRef] [PubMed]

18. Kuliev, A.; Zlatopolsky, Z.; Kirillova, I.; Spivakova, J.; Janzen, J.C. Meiosis errors in over 20,000 oocytes studied in the practice of preimplantation aneuploidy testing. Reprod. Biomed. Online 2011, 22, 2-8. [CrossRef] [PubMed]

19. The ESHRE Guideline Group on Ovarian Stimulation; Bosch, E.; Broer, S.; Griesinger, G.; Grynberg, M.; Humaidan, P.; Kolibianakis, E.; Kunicki, M.; La Marca, A.; Lainas, G.; et al. ESHRE guideline: Ovarian stimulation for IVF/ICSI. Hum. Reprod. Open. 2020, 2020, 1-13. [CrossRef]

20. DIppolito, G.; Tirelli, A.; Giulini, S.; Volpe, A.; La Marca, A. Hormonal and ultrasound markers of ovarian function in a woman with a balanced 1;11 translocation. Fertil. Steril. 2011, 95, 803.e7-803.e8. [CrossRef]

21. Keymolen, K.; Staessen, C.; Verpoest, W.; Michiels, A.; Bonduelle, M.; Haentjens, P.; Vanderelst, J.; Liebaers, I. A proposal for reproductive counselling in carriers of Robertsonian translocations: 10 years of experience with preimplantation genetic diagnosis. Hum. Reprod. 2009, 24, 2365-2371. [CrossRef] [PubMed] 
22. Weenen, C.; Laven, J.S.; Von Bergh, A.R.; Cranfield, M.; Groome, N.P.; Visser, J.A.; Kramer, P.; Fauser, B.C.; Themmen, A.P. Anti-Müllerian hormone expression pattern in the human ovary: Potential implications for initial and cyclic follicle recruitment. Mol. Hum. Reprod. 2004, 10, 77-83. [CrossRef] [PubMed]

23. Visser, J.A.; Themmen, A.P.N. Anti-Müllerian hormone and folliculogenesis. Mol. Cell. Endocrinol. 2005, 234, 81-86. [CrossRef] [PubMed] 